\title{
ANALISIS KEBUTUHAN MODUL PEMBELAJARAN IPA BERORIENTASI PENDIDIKAN KARAKTER MELALUI PENDEKATAN QUANTUM LEARNING DI SEKOLAH DASAR
}

\author{
Rona Taula Sari ${ }^{1}$ \\ Ira Rahmay uni Jusar ${ }^{2}$ \\ ${ }^{1,2}$ Program Studi Pendidikan Guru Sekolah Dasar, FKIP Universitas Bung Hatta \\ E-mail: ronataulasari21@g mail.com
}

\begin{abstract}
In the learning process, teachers are expected to comprehend how to manage the learning activity including class, students, learning activities, contents and resources of learning. So that in the learning process, students will be active and give a good response to the ongoing learning process. This research is descriptive research that conducted on student grade $V$ in Elementary School Number 5 Tan Malaka Padang. The research method is CIPP that observe four dimensions, They are context, input, process and product dimension. Data from observation and interview will be processed by describing way and analyzing the data until find conclusion. From the result of the research, it is detected that module which will be used for science learning process on the subject of Digestion System is learning module which oriented to character education through Quantum Learning Approach, based on curriculum, student character and concept overview. The conclusion of this research is the analysis of necessity of learning model for science learning with character education oriented through Quantum Learning Approach using CIPP model that is context dimension analyzing on curriculum, student, and concept. The learning process will use learning module Science of character oriented through Quantum Learning on input dimension. Meanwhile, the module of the process and product dimension used refers to existing measures on Quantum Learning with full-color display model in line with the character of the student.
\end{abstract}

Kata kunci : In kuiri terbimb ing, lesson study, keanekaragaman hewan

\begin{abstract}
Pendidikan merupakan suatu kegiatan yang universal dalam kehidupan manusia. Menurut UndangUndang Sistem Pendidikan Nasional (UUSPN) Bab 1, Pasal 1 dinyatakan bahwa: "Pendidikan adalah usaha sadar dan terencana untuk mewujudkan suasana belajar dan proses pembelajaran agar peserta didik secara aktif mengembangkan potensi dirinya untuk memiliki kekuatan spiritual keagamaan, pengendalian diri, kepribadian, kecerdasan, akhlak mulia, serta keterampilan yang diperlukan dirinya, masyarakat, bangsa dan negara". Pendidikan menduduki posisi sentral dalam semua bidang pembangunan karena sasarannya
\end{abstract}

adalah peningkatan kualitas sumber daya manusia (SDM).

Peningkatan kualitas SDM dapat dilakukan dengan meningkatkan mutu pendidikan seperti perbaikan kurikulum, pemerataan tenaga kependidikan, peningkatan proses belajar mengajar, penambahan sarana dan prasarana pendidikan serta berbagai upaya lainnya. Peningkatan kualitas SDM dapat dilakukan dengan meningkatkan mutu pendidikan seperti perbaikan kurikulum, pemerataan tenaga kependidikan, peningkatan proses belajar mengajar, penambahan sarana dan prasarana pendidikan serta berbagai upaya lainnya. 
Kurikulum Tingkat Satuan Pendidikan (KTSP) yang memberi otonomi luas kepada sekolah dan satuan pendidikan, disertai perangkat dan tanggung jawab untuk mengembangkan kurikulum sesuai dengan kondisi setempat. Melalui KTSP sekolah dan satuan pendidikan juga diberi kewenangan dan kekuasaan yang luas untuk mengembangkan pembelajaran sesuai dengan kondisi dan kebutuhan siswa serta tuntutan masyarakat.

Selain itu, sekolah dan satuan pendidikan juga diberi kewenangan untuk menggali dan mengelola sumber dana sesuai dengan prioritas kebutuhan. Melalui otonomi yang luas, sekolah dapat meningkatkan kinerja tenaga kependidikan dengan menawarkan partisipasi aktif mereka dalam pengambilan keputusan dan tanggung jawab bersama dalam pelaksanaan keputusan yang diambil secara proporsional dan profesional (Mulyasa, 2007: 29-30). Menurut Admin (2007: 6) melalui kebijakan KTSP, sekolah diberi kebebasan menyusun kurikulum sendiri sesuai dengan konteks lokal, kemampuan siswa dan ketersediaan saranaprasarana. Tujuannya adalah agar potensi tiap-tiap sekolah dapat menonjol.

Selama pelaksanaan KTSP, guru dituntut harus mampu menyusun perangkat pembelajaran sendiri sesuai dengan kondisi sekolah dan karakter siswa. Hal ini bertujuan untuk menentukan arah kegiatan pembelajaran yang dilakukan guru dan dapat menanamkan nilai-nilai karakter kepada siswa. Perangkat pembelajaran yang dibuat guru diharapkan dapat menunjang penerapan KTSP demi mencapai tujuan pendidikan nasional yaitu menghasilkan lulusan yang unggul dan berakhlak mulia dari sekolah tersebut.

\section{Menurut}

Woolfolk (Muhammad, 2006), dibutuhkan tiga kondisi untuk terlaksananya pembelajaran dengan baik yaitu: 1) Siswa harus memiliki berbagai sumber untuk pelaksanaan pembelajaran. Sumber yang dimaksud adalah perangkat pembelajaran, guru, masyarakat, dukungan keluarga, bekal pengetahuan dan pengalaman awal, 2) Siswa harus memiliki kesempatan dalam belajar. Ini berarti waktu yang cukup untuk demonstrasi, diskusi dan proyek; kesempatan untuk mengklarifikasi konsep-konsep; dan tantangan-tantangan belajar yang akan mencegah terjadinya kesalahpahaman pengertian. Berikutnya Siswa harus dapat mengambil manfaat dari sumbersumber pembelajaran dan kesempatan belajar. Siswa harus menaruh perhatian, berbicara dengan guru dan siswa lain dan menyatakan suatu pemahaman atas konsep-konsep kunci secara lisan serta tertulis.

Secara khusus, dalam pembelajaran IPA guru diharapkan dapat memahami bagaimana menyediakan pengalaman belajar yang beragam baik dari pengalaman mental, fisik, maupun sosial, karena pembelajaran IPA ditekankan pada pemberian pengalaman langsung untuk mengembangkan karakter dan potensi siswa. Selain itu, guru diharapkan dapat memahami bagaimana mengelola kegiatan pembelajaran yang efektif yang terkait dengan tempat belajar, siswa, kegiatan pembelajaran, isi/ materi pembelajaran dan sumber belajar sehingga dalam proses pembelajaran siswa akan aktif dan menunjukkan respons yang baik terhadap proses pembelajaran yang sedang berlangsung.

Berdasarkan permasalahan tersebut maka penulis ingin melakukan analisis kebutuhan modul pembelajaran IPA berorientasi Pendidikan Karakter 
melalui pendekatan Quantum Learning di Sekolah Dasar siswa kelas V semester 1. Adapun tujuan penelitian untuk mengetahui kebutuhan modul pembelajaran IPA berorientasi Pendidikan Karakter melalui pendekatan Quantum Learning di Sekolah Dasar.

\section{METODE}

Penelitian ini adalah penelitian deskriptif. Penelitian deskriptif ini bertujuan untuk memecahkan masalah aktual yang dihadapi serta bertujuan untuk mengumpulkan data/informasi untuk disusun, dijelaskan dan dianalisis, Arikunto (2006). Penelitian dilaksanakan pada siswa kelas V SD N 05 Tanmalaka Padang. Metode penelitian yang digunakan adalah teknik evaluasi model CIPP (Context input - process - product) (Widoyoko, 2013). Mahmudi (2011) menyatakan bahwa Model CIPP melihat kepada empat dimensi yaitu dimensi Konteks, dimensi Input, dimensi Proses dan dimensi Produk. Adapun teknik pengumpulan data dengan menggunakan instrumen dan observasi. Data yang diperoleh dari observasi dan wawancara diolah dengan cara mendeskripsikan dan menganalis is data tersebut sampai diperoleh kesimpulan. Penarikan kesimpulan yang dilakukan dapat menjawab rumusan masalah yang telah dirumuskan yaitu bagaimana kebutuhan modul pembelajaran IPA berorientasi pendidikan karakter melalui pendekatan Quantum Learning?.

\section{HASIL DAN PEMBAHASAN \\ a. Dimensi Konteks}

1. Analisis Kurikulum

Analisis kurikulum difokuskan pada analisis SK dan KD untuk materi sistem pencernaan sebagaimana yang tercantum pada Standar Isi (SI). SK pertama yang terdapat pada
Permendiknas Nomor 22 tahun 2006 adalah: Mengidentifikasi fungsi organ tubuh manusia dan hewan. Sedangkan KD pada materi sistem pencernaan adalah KD 1.3 yaitu; mengidentifikasi fungsi organ pencernaan manusia dan hubungannya dengan makanan dan kesehatan.

Hasil analisis SK dan KD tentang materi sistem pencernaan yang terdapat pada Standar Isi, dijabarkan menjadi indikator-indikator pembelajaran dan tujuan pembelajaran. Indikator yang dirumuskan adalah sebagai berikut.

1. Menjelaskan struktur alat pencernaan makanan manusia.

2. Menjelaskan fungsi alat pencernaan makanan manusia.

3. Menjelaskan enzim yang dihasilkan kelenjar pencernanan makanan

4. Mengidentifikasi zat-zat makanan dalam bahan makanan yang dikonsumsi sehari-hari.

5. Mendeskripsikan kebutuhan energi bagi tubuh dan mengaitkannya dengan asupan nilai gizi makanan siswa pada menu seimbang.

6. Mengemukakan kemungkinan kelaian/penyakit yang dapat terjadi pada sistem pencernaan manusia.

7. Mengemukakan cara menghindari kelainan/penyakit pada sistem pencernaan manusia.

Penjabaran SK, KD, dan indikator pencapaian kompetensi menjadi pertimbangan untuk menentukan konsep-konsep yang diperlukan dalam pembelajaran IPA pada materi sistem pencernaan dan mengukur pencapaian SK dan KD. Dari perumusan indikator diatas diketahui bahwa pembelajaran pada materi sistem pencernaan dapat didukung dengan memfasilitasi 
lingkungan belajar siswa dengan membangun keterkaitan pembelajaran dalam kehidupan sehari-hari siswa sehingga pengintegrasian nilai-nilai karakter kepada siswa mudah dilaksanakan dan di aplikasikan dalam kehidupan nyata mereka melalui pendekatan Quantum Learning. Zubaedi (2011:291) menyatakan bahwa upaya menanamkan nilai-nilai karakter kepada peserta didik dapat diintegrasikan dalam setiap mata pelajaran, salah satunya adalah Ilmu Pengetahuan Alam (IPA).

Mata pelajaran IPA diharapkan dapat menjadi wahana bagi peserta didik untuk mempelajari diri sendiri dan alam sekitar, serta prospek pengembangan lebih lanjut untuk menerapkannya dalam kehidupan sehari-hari. Mata pelajaran IPA tidak hanya berhubungan dengan bagaimana memahami alam secara sistematis, tetapi juga merupakan wadah mengembangkan karakter bagi peserta didik (Sari, 2014:93).

2. Analisis Siswa

Analisis siswa dijadikan sebagai gambaran untuk mengembangkan modul pembelajaran IPA berorientasi Pendidikan Karakter melalui pendekatan Quantum Learning untuk SD Kelas V Semester I. Analisis siswa ini meliputi usia, minat dan bakat siswa, kehidupan sosial, serta kecenderungan gaya belajar maupun kemampuan dasar yang dimiliki oleh siswa SD. Dalam penelitian ini yang menjadi subjek adalah siswa SD N 05 Sawahan Padang yang rata-rata berusia antara 10-12 tahun adalah siswa yang berada pada tahapan kanak-kanak akhir.

Usia ini ditandai dengan siswa sudah berusaha untuk mencapai sesuatu, tetapi perkembangan aktivitas bermain hanya bertujuan untuk mendapatkan kesenangan (Djamarah, 2011: 123). Izzaty (2008: 116) membagi masa anak-anak di Sekolah Dasar menjadi dua fase yaitu masa anak kelas rendah (kelas I sampai dengan kelas III), dan masa anak kelas tinggi (kelas IV sampai dengan kelas VI). Masa anak kelas rendah berlangsung antara usia 7-9 tahun, sedangkan masa anak kelas tinggi berlangsung antara usia 9-12 tahun. Kelas IV Sekolah Dasar tergolong pada masa anak kelas tinggi.

Suryobroto (Djamarah, 2011: 125) menyebutkan beberapa karakteristik siswa kelas tinggi sekolah dasar adalah:

a. adanya minat terhadap kehidupan praktis sehari-hari yang konkret, hal ini menimbulkan adanya kecerendungan untuk membandingkan pekerjaanpekerjaan yang praktis;

b. amat realistik, ingin tahu, dan ingin belajar;

c. menjelang akhir masa ini telah ada minat terhadap hal-hal dan mata pelajaran khusus yang oleh para ahli ditafsirkan sebagai mulai menonjolnya faktor-faktor;

d. sampai kira-kira umur 11 tahun, anak membutuhkan guru atau orang-orang dewasa lainnya; serta

e. siswa pada masa ini gemar membentuk kelompok sebaya, biasanya untuk dapat bermain bersama-sama.

Dari pendapat di atas, dapat disimpulkan bahwa anak kelas V SD merupakan usia di mana keterampilan motorik ataupun kognitifnya berkembang dengan baik terhadap lingkungan sekitar sehingga guru harus memperhatikan dengan baik dan mampu merangsang siswa agar keterampilannya berkembang lebih baik melalui kegiatan-kegiatan yang diselenggarakannya. Hal senada dari Sari (2015:214) Quantum Learning memanfaatkan berbagai variasi sumber belajar dan kegiatan belajar. Asas 
utama yang digunakan dengan membawa siswa ke dunia guru, dan mengantarkan guru ke dunia siswa, mengingatkan pentingnya memasuki dunia siswa untuk memudahkan menuntun pembelajaran menuju kesadaran dan ilmu pengetahuan yang akan didapat. Proses pembelajaran yang dilakukan dikaitkan dengan peristiwa, pikiran, atau perasaan yang diperoleh dari kehidupan dirumah, sosial, musik, seni, rekreasi, atau akademis siswa. Sehingga penanaman nilai-nilai karakter dapat dilaksanakan dengan mudah dan tepat melalui pendekatan Quantum Learning.

\section{Analis is Konsep}

Analis is konsep merupakan dasar untuk menentukan konsep-konsep utama dari materi sistem Pencernaan. Konsep-konsep penting yang harus dipahami siswa dalam mempelajari materi sistem pencernaan antara lain seperti berikut.

1. Rongga mulut (cavum oris)

2. Faring (farink)

3. Kerongkongan (oesophagus)

4. Lambung (ventriculus)

\section{b. Dimensi Input}

Berdasarkan uraian di atas, dapat diketahui bahwa penggunaan Quantum Learning dalam pembelajaran dapat mendorong siswa mempunyai kemauan untuk belajar dan mengembangkan suasana yang menyenangkan dalam pembelajaran dengan partisipasi aktif siswa. Quantum Learning memungkinkan siswa untuk belajar dengan kecepatan mengesankan, upaya yang normal, dan disertai kegembiraan. Quantum Learning mampu menyatukan unsurunsur yang secara sekilas tidak nampak mempunyai persamaan, seperti hiburan, permainan, warna, cara berpikir positif, kebugaran fisik, dan kesehatan emosional menjadi pengalaman belajar yang efektif
5. Usus halus (intestinum tenue)

6. Usus Besar (intestinum crassum)

7. Rektum (rectum)

8. Anus

9. Usus dua belas jari (duodenum)

10. Usus kosong (jejunum)

11. Usus penyerapan (ileum)

12. Enzim pencernaan

13. Air ludah (saliva)

14. Gigi susu

15. Gigi permanen

16. Pencernaan fisika

17. Pencernaan kimiawi

18. Email

19. Dentin

20. Pulpa

21. Amilase ludah (ptialin)

22. Pepsin

23. Renin

24. Tripsin

25. Lipase

26. Amilase pankreas

27. Hati

28. Empedu

29. Feses (faeces)

30. Peristaltik

(DePorter dan Hernacki, 2000:14). Namun, Quantum Learning yang telah terbukti memberikan banyak keunggulan dalam pembelajaran belum banyak diterapkan oleh guru-guru yang dibuktikan dengan sedikitnya hasil penelitian yang memaparkan tentang pemanfaatannya. Pada pembelajaran IPA, Quantum Learning baru dicobakan pada beberapa materi pokok saja, dan belum ditemukan pengembangannya pada materi Sistem Pencernaan Makanan (Sari, 2015:215).

\section{c. Dimensi Proses}

Pembelajaran IPA memiliki hakikat perencanaan atau perancangan (desain) sebagai upaya untuk membelajarkan siswa dalam mencapai tujuan pembelajaran. Segala sesuatunya berarti, setiap kata, pikiran, 
tindakan, dan asosiasi, dan sampai sejauh mana guru dapat menggubah lingkungan, penyajian, dan perancangan pembelajaran. Pembelajaran secara eksplisit terdiri atas kegiatan memilih, menetapkan, mengembangkan metode untuk mencapai hasil yang diinginkan. Pemilihan pengembangan didasarkan atas kondisi pembelajaran yang ada. Siswa diharapkan tidak hanya melakukan interaksi dengan guru sebagai satu-satuya sumber belajar, namun juga dengan keseluruhan sumber belajar yang mungkin digunakan untuk mencapai tujuan pembelajaran yang diinginkan. Oleh karena itu pembelajaran diupayakan untuk memusatkan perhatian pada "bagaimana membelajarkan siswa" dan bukan pada "apa yang dipelajari siswa" (Uno, 2011:84).

Sari (2015:214) Implementasi strategi Quantum Learning dapat dilakukan pada pembelajaran IPA karena memiliki karakteristik yang cocok dengan prinsip-prinsip Quantum Learning. Materi - materi dalam pembelajaran IPA memiliki cakupan yang cukup luas hingga memerlukan pemahaman yang holistik. Hal pertama yang dapat dilakukan melalui mengetahui manfaat materi pelajaran yang dipelajari dan menghubungkan dengan contoh kehidupan siswa. Pemahaman materi dapat dituntun secara konstruktivistik dengan melibatkan siswa secara aktif dalam memperoleh informasi. Selain itu, dengan menggunakan cara yang memudahkan siswa untuk mengingat, seperti: sistem akronim, kalimat kreatif, atau jembatan keledai (pneumonic).

\section{d. Dimensi Produk}

Modul

pembelajaran

IPA

mengarah pada model Quantum Learning dengan memanfaatkan penataan lingkungan belajar, penyediaan pengalaman belajar, memanfaatkan kekuatan motivasi intrinsik siswa, menerapkan prinsip Tandur, memupuk sikap juara, memfasilitasi modalitas belajar, memudahkan kemampuan mengingat dengan sistem akronim dan kalimat kreatif, membiasakan mencatat dengan simbol, dan melatih kekuatan memori dengan menggunakan Mind Map.

Pemanfaatan kekuatan Ambak dan prinsip Tandur. Subbab diberikan warna berbeda dibanding uraian materi dengan ukuran yang lebih menonjol. Penjabaran materi disertai dengan gambar-gambar yang mendukung konsep. Penegasan materi dalam bentuk konsep, fakta, prinsip, atau prosedur ditegaskan pada tempattempat khusus. Kata-kata kunci pada materi diberi warna yang berbeda dibandingkan dengan teks lain. Setiap akhir materi pembelajaran pada indikator terdapat pengulangan katakata kunci dan refleksi untuk pengecekan pemahaman siswa untuk memastikan bahwa siswa memang tahu. Poster afirmasi terdapat pada akhir subbab untuk tetap memberikan motivasi bagi siswa. Tampilan latar belakang fullcolour dan dominan menggunakan warna jingga yang mendukung proses pembelajaran.

\section{KESIMPULAN}

Berdasarkan hasil yang diperoleh dapat disimpulkan bahwa analisis kebutuhan modul pembelajaran IPA berorientasi pendidikan karakter melalui pendekatan Quantum Learning dengan mengunakan model CIPP yaitu dimensi konteks menganalisis pada kurikulum, siswa dan konsep. Proses pembelajarn akan menggunakan modul pembelajaran IPA berorientasi pendidikan karakter melalui pendekatan Quantum Learning pada dimensi input. Sementara itu, dimensi Proses dan Produk Modul yang digunakan mengacu kepada langkah- 
langkah yang telah tersedia pada pendekatan Quantum Learning dengan tampilan modul yang Fullcolor disesuaikan dengan karakteristik siswa.

\section{DAFTAR PUSTAKA}

Admin. 2007. Kurikulum Beridentitas Kerakyatan.

http://denbagustomy. wordpress.com/2007/07/04/kurik ulum-beridentitas-kerakyatan. Diakses: 2 Maret 2017.

Arikunto, S. 2013. Dasar-Dasar Evaluasi Pendidikan. Jakarta: Bumi Aksara.

DePorter, B.dan M. Hernacki, 2000. Quantum Learning: Membiasakan Belajar Nyaman Dan Menyenangkan. Bandung: Kaifa.

Izzaty, R. E. 2008. Perkembangan Peserta Didik. Yogyakarta: UNY Press.

Mahmudi, I. 2011. CIPP Suatu Model Evaluasi Program Pendidikan. Jurnal At-Ta'dib Vol. 6, No. 1, Juni 2011.

Mulyasa, E. 2007. KurikulumTingkat Satuan Pendidikan. Bandung: Rosda Karya.

Muhammad, N. 2006. Contoh Proposal Penelitian Pengembangan. Makalah, Disampaikan pada Workshop Pengembangan Model dan Strategi Pembelajaran Berorientasi Life Skill di Jurusan Studi Fisika dan Peningkatan Pengetahuan Dosen dalam Melakukan Penelitian Pengembangan di Jurusan Biologi FMIPA Universitas Negeri Padang pada tanggal 2729 Juni 2006.

Sari, R. T. 2014. Pengembangan Perangkat Pembelajaran Berorientasi Pendidikan Karakter dalam Pembelajaran IPA SMK. Jurnal Penelitian dan Kajian Ilmiah Menara Ilmu, Vol III No. 46, Mar 2014 ISSN 1693-2617.

Sari, R. T. 2015. Penggunaan Metode Quantum Learning untuk Meningkatkan Aktivitas Belajar IPA S is wa Sekolah Dasar. Jurnal Cerdas Proklamator, Vol 3, No 2 Desember 2015 ISSN 2338-0926.

Djamarah, B. S. 2006. Strategi Belajar Mengajar. Rineka Cipta: Jakarta.

Uno, H. 2007. Perencanaan Pembelajaran. Jakarta : Bumi Aksara

Widoyoko, S. E. P. 2013. Evaluasi Program Pembelajaran, Panduan Praktis Bagi Pendidik dan Calon Pendidik. Yogyakarta: Pustaka Pelajar.

Zubaedi. 2011. Desain Pendidikan Karakter. Jakarta: Kencana. 